\title{
EVALUATION OF BENEFICIAL EFFECTS OF LINUM USITATISSIMUM IN CONGESTIVE HEART FAILURE
}

\author{
PRAVIN TIRGAR, LIMBASIYA KALPESH \\ School of Pharmacy, RK University, Rajkot, Gujarat, India \\ Email: pravin.tirgar@rku.ac.in \\ Received: 06 Jun 2017 Revised and Accepted: 31 Aug 2017
}

\begin{abstract}
Objective: Evaluation of beneficial effects of the seed of Linum usitatissimum in congestive heart failure.

Methods: Methanolic extract of seeds of Linumusitatissimum (MELU) was prepared using soxhlet apparatus and oil of seed of Linumusitatissimum (OLU) was isolated using Clevenger apparatus. The positive inotropic action of methanolic extract of seeds of Linum usitatissimum was evaluated using Langendorff's assembly (in vitro study). Beneficial effects of methanolic extract and oil of seeds of Linum usitatissimum were carried out by doxorubicin ( $1 \mathrm{mg} / \mathrm{kg}$, i. p. within $3 \mathrm{w}$ ) to induce congestive heart failure (in vivo study). Parameters like electrocardiogram (ECG) recording and cytosolic $\mathrm{Ca}^{2+}$ level and histopathology of the heart were carried out. In same study diuretic action was evaluated using Lipschitz model.

Results: Methanolic extract of seeds of Linum usitatissimum showed significantly increased in positive inotropic effect (force of contraction $48.8 \pm 1.53 \mathrm{~mm}$ ) as compared to control group (force of contraction $17.5 \pm 0.76 \mathrm{~mm}$ ) on Langendorff"s study (in vitro study). In doxorubicin-induced congestive heart failure both MELU and OLU showed significant decreased QT (Note: In cardiology, the QT interval is a measure of the time between the start of the $Q$ wave and the end of the $T$ wave in the heart's electrical cycle. There is no full form for this medical word) interval. The histopathologic study indicated the least damage to the architecture of myocardial membrane. MELU and OLU increased urine output ( $5.66 \pm 0.16 \mathrm{ml}$ and $6.58 \pm 0.15 \mathrm{ml}$ respectively) significantly in Lipschitz model as compared to disease control group (4.58 $\pm 0.15 \mathrm{ml})$.
\end{abstract}

Conclusion: Present research work emphasizes that the seeds of Linum usitatissimum is beneficial in the management of congestive heart failure because of having positive inotropic effect, diuretic activity and control of rhythmicity of heart.

Keywords: Seeds of Linum usitatissimum, Langendorff's assembly, Positive inotropic, Diuretic action, Congestive heart failure

(C) 2017 The Authors. Published by Innovare Academic Sciences Pvt Ltd. This is an open-access article under the CC BY license (http://creativecommons.org/licenses/by/4.0/) DOI: http://dx.doi.org/10.22159/ijpps.2017v9i10.20534

\section{INTRODUCTION}

Heart failure is a common chronic disease that leads to disability and death. It is the only major cardiovascular disease that has increasing incidence and prevalence [1 12$]$.

Treatment strategies have been focused mainly on the use of diuretics and cardiac glycosides. Although, such therapies relieve symptoms of the disease and stabilize patients but rarely improve survival [3]

Plants have been utilized as medical treatments since the beginning of civilization, however, in $20^{\text {th }}$ century the herbal medicine has been losing ground to new synthetic medicines [4]. This fact occurs, at least in part, by failure in scientific data about the biological effects of the plants. It is important that the physicians may have more information about beneficial and adverse effects of the plants [5]. The herbal medicine is utilized routinely to the treatment of cardiovascular disease as congestive heart failure, hypertension and angina pectoris [4]. Ayurveda is a traditional and most commonly practised form of medicine in India [6]. Ayurveda has given different plants and formulations, which are useful in managing heart diseases [7]. Flax (Linum usitatissimum) is an ancient crop that is widely cultivated as a source of fiber, oil and medicinally relevant compounds $[8,9]$. The seed of flax (i.e. linseed) produces oil that is rich in unsaturated fatty acids, especially $\alpha$-linolenic acid (C18:3), polymers of which are used in linoleum, paints and other finishes. Consumption of the oil or seed has been reported to have beneficial effects on cardiovascular health and in the treatment of certain cancers and inflammatory diseases [10]. Health benefits are derived from both the $\alpha$-linolenic acid and other components of the seed, including lignans such as secoisolariciresinol diglucoside (SDG), which is an antioxidant and the precursor of several phytoestrogens [11]. Flaxseed is also used in animal feed to increase levels of $\alpha$-linolenic acid in meat or eggs [12].

The objective of the present study was focused on the evaluation of new herbal drug having potent cardiotonic activity and having beneficial in CHF and other cardiovascular complications with least adverse effects. So, looking for the dire need of a new safe and economical cardiotonic molecule, we resolved to investigate beneficial effect of Linum usitatissimum responsible for its cardiotonic activity.

\section{MATERIALS AND METHODS}

\section{Collection and authentication}

The seed of Linum usitatissimum used in the present study was acquired from "Anand Agriculture University" at Anand, Gujarat which was collected from the local region of Anand. Herbarium of the research drug was prepared and authenticated by Prof. Vishal Muliya, at Head of Botany Department, Christ College, Rajkot, Gujarat, India (voucher specimen number RKCP/Col/R01/2015).

Methanolic extract of fine powder of seeds of Linum usitatissimum was prepared using soxhlet apparatus. Oil of seed was separated using soxhlet apparatus using petroleum ether (Oxford laboratory reagent, Mumbai) as a solvent. All the experimental procedures and protocols used in study was reviewed and approved by the Institution Animals Ethical Committee (IAEC) of School of Pharmacy, RK University, and care of laboratory animals were taken as per the guidelines of Committee for the Purpose of Control and Supervision of Experiments on Animals (CPCSEA), Government of India.(Approval no. RKCP/COl/RP/16/69). Healthy adult Wistar Albino rats $(250-300 \mathrm{gm})$ were selected for the study. The animals were acclimatized to standard laboratory conditions (temperature: $\left.25 \pm 5{ }^{\circ} \mathrm{C}\right)$, humidity $(55 \pm 5 \%)$ and maintained on a 12 -h light: 12 -h dark cycle. They were provided with regular rat chow and drinking water adlibitum.

Evaluation of cardiotonic activity of seed of Linum usitatissimum using langendorff's apparatus: (in vitro study)

Isolated wistar rat heart was mounted on Langendorff's Apparatus and force of contraction, heart rat were recorded for methanol 
(Oxford laboratory reagent, Mumbai) and oil extracts of Linum usitatissimum $[13,14]$

\section{Evaluation of beneficial effects of seed of Linum usitatissimum on} doxorubicin Induced congestive heart failure model. (in vivo study)

Doxorubicin-induced cardiomyopathy may result in progressive heart failure after antineoplastic therapy, thus limiting the application of this potent chemotherapeutic agents. The mechanisms of cardiac toxicity are thought to include heightened oxidative stress status and apoptosis of endothelial cells and cardiomyocytes [15]

Wistar rats of either sex initially weighing 220-280 gm were used for the present study. For induction of congestive heart failure, doxorubicin (Cipla Limited) was administered $1 \mathrm{mg} / \mathrm{kg}$, i. p. for 10 times in $3 \mathrm{w}$ on every alternative days. The other groups were receiving their respective treatment along with doxorubicin $[15,16]$.

The experimental animals were divided into five groups each having 6 animals.

Group 1-Normal control: receive water only ad libitum

Group 2-Disease control: doxorubicin (1 mg/kg, i. p.)

Group 3-Standard control: doxorubicin+digoxin $(100 \mu \mathrm{g} / \mathrm{kg} /$ day, p. o., per day)

Group 4-Test control A: doxorubicin+Methanolic extract of seeds of Linum usitatissimum (500 mg/kg/day, p. o., per day)

Group 5-Test control B: doxorubicin+oil of seeds of Linum usitatissimum $(0.6 \mathrm{ml} / \mathrm{kg} /$ day, p. o., per day)

The study was carried out for a period of $3 \mathrm{w}$. At the end of $3 \mathrm{w}$, diuretic activity was evaluated using Lipschitz model and then ECG patterns were recorded [17]. Isolated hearts were preserved in $10 \%$ formalin (Oxford laboratory reagent, Mumbai) for histopathological study [18-21].

\section{ECG recording}

ECG was recorded after $24 \mathrm{~h}$ of the last dose of doxorubicin. All animals fasted overnight with free access to water. NIBP-200 was used for recording and monitoring of ECG tracing. Rats from each group were anaesthetized by diazepam (Ranbaxy Diagnostics) 0.5 $\mathrm{mg} / \mathrm{kg}$, i. m.) followed by ketamine (Sun Pharma Ltd.) (0.1 ml/100 gm, i. p.). Needle electrodes were inserted under the skin of chest area. II (Lead II: Insert one needle in the left side and insert another in the right side and also one grounder needle inserted under the skin of left thigh area. Mainly P wave, QRS complex, QT interval were observed and compared for all four groups [22].

\section{Histopathology}

Histopathological study of heart was carried out to study the protective effects of a Methanolic extract of Linum usitatissimum and oil of Linum usitatissimum in doxorubicin-induced congestive heart failure on animals.

\section{Diuretic activity}

After regular treatment to respective animals of a different group, animals were placed in the five different metabolic cages for a period of $24 \mathrm{~h}$. A beaker cover with aluminium foil to prevent from evaporation. Urine samples were collected in a measuring cylinder and volume of urine collected from each metabolic cage was recorded to evaluate the diuretic action of seeds of Linum usitatissimum [23].

\section{Statistical analysis}

To check the significance of data, following statistical tests were performed:

ANOVA: to see the variability within all the groups.

Tuckey's test: for the same purpose mentioned in above test.

INSTAT software: to derive all statistical terms like Standard Error of Mean (SEM),

ANOVA, P-value, Degree of freedom, Standard deviation, etc.

Data were considered statistically significant at $\mathrm{p}<0.05$ and highly significant at $\mathrm{p}<0.001$. Statistical analysis was performed using INSTAT statistical software.

\section{RESULTS AND DISCUSSION}

Beneficial effects of digoxin and MELU on force of contraction of isolated rat heart-langendorff's assembly-in vitro study

In isolated rat heart preparation on Langendorff's assembly, methanolic extract of seeds of Linum usitatissimum (MELU) showed significant increase in force of contraction when compared to normal response. This indicates that MELU possesses positive inotropic effect which can reduce the preload in the heart.

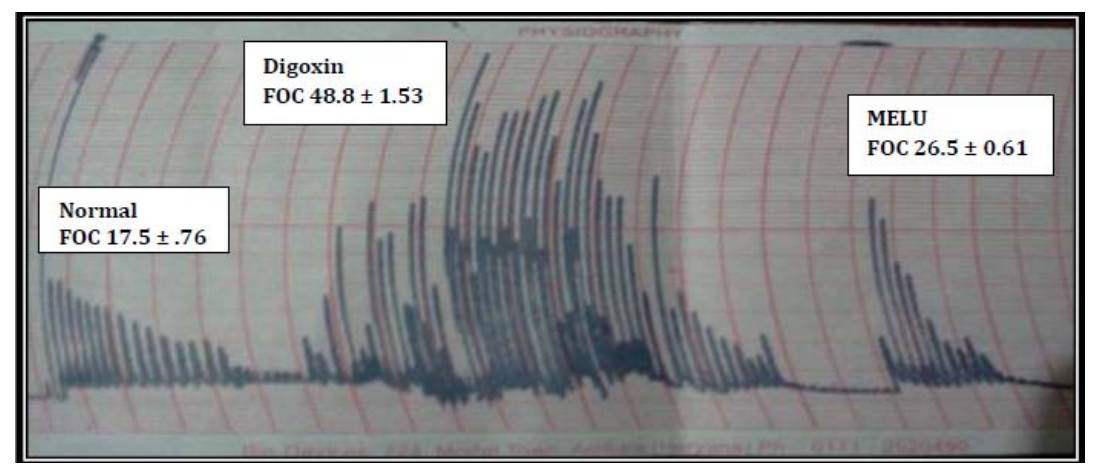

Fig. 1: Positive inotropic action of methanolic extract of seeds of linum usitatissimum (MELU)

Table 1: Effect of methanolic extract of seeds of Linum usitatissimum (MELU) on force of contraction

\begin{tabular}{lll}
\hline Groups & Force of contraction $\mathbf{( m m )}$ & \% Force of contraction \\
\hline Control & $17.5 \pm 0.76$ & $100 \pm 0.5$ \\
Digoxin & $48.8 \pm 1.53^{*}$ & $281.44 \pm 13.34^{*}$ \\
MELU & $26.5 \pm 0.61^{*}$ & $152.5 \pm 5.49^{*}$ \\
$F$ & 234.65 & 125.54 \\
$d f$ & $17(2,15)$ & $17(2,15)$ \\
$P$ & $<0.001$ & $<0.001$ \\
\hline
\end{tabular}

$\mathrm{n}=6$, Results were shown as mean \pm SEM, Normal-height in $\mathrm{mm}$ on physiography paper, Digoxin-received digoxin (50 $\mu \mathrm{g} / \mathrm{ml}-0.2 \mathrm{ml}$ ), MELU-received methanolic extract of seeds of Linum usitatissimum, (MELU: $500 \mathrm{mg} / \mathrm{ml}-0.2 \mathrm{ml}$ ), * indicate significant difference in the data compared to control group and the level of significance was $\mathrm{p}<0.001 \approx$ highly significant. 
Beneficial effects of digoxin and methanolic extract of seeds of Linum usitatissimum on ECG pattern of rats in doxorubicininduced congestive heart failure model-in vivo study

Doxorubicin can cause cardiotoxicity which results in changes in ECG pattern and thus ECG was monitored in all five groups. Doxorubicin causes prolongation of $\mathrm{P}$ wave, QRS complex, QT interval, ST elevation and reduces cardiac cycles. In disease control group, QT interval was prolonged which is a marker of hypertrophy of ventricles i.e. increased ventricular diameter [24]. The ST elevation may be observed due to cellular membrane damage occurred by oxidative stress [25]. Test groups, treated with MELU and OLU, reflected the least prolongation of QT interval significantly compared to disease control group. These findings suggest that MELU is effective to avoid cardiac damage occurred by doxorubicin.

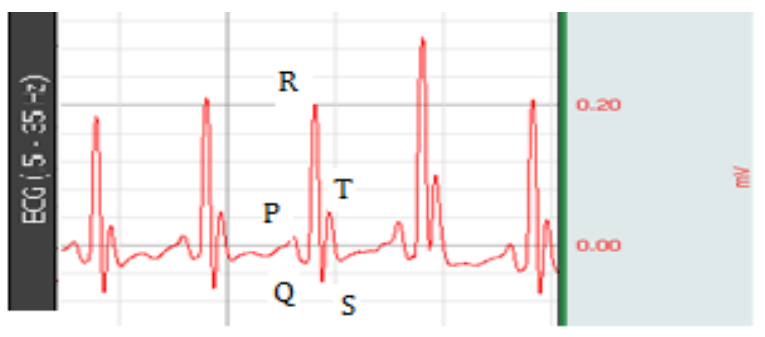

Fig. 2 (I): Effects of vehicle on QT interval in ECG of normal control group

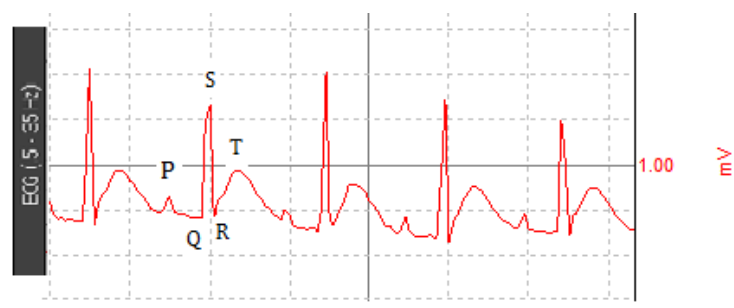

Fig. 2 (II): Effects of doxorubicin on QT interval in ECG of disease control group

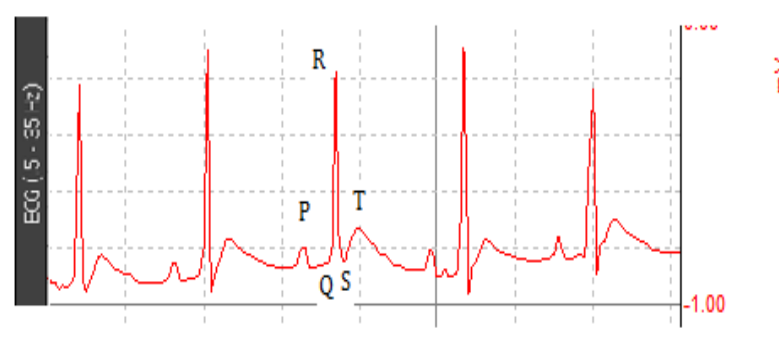

Fig. 2 (III): Effects of digoxin on QT interval in ECG of standard control group

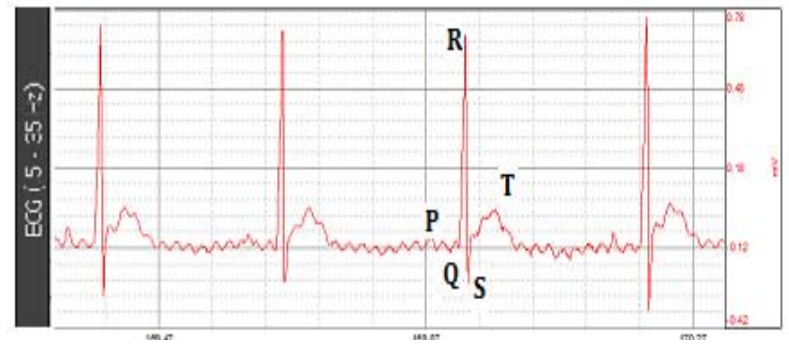

Fig. 2 (IV): Effects of MELU on QT interval in ECG of MELU group

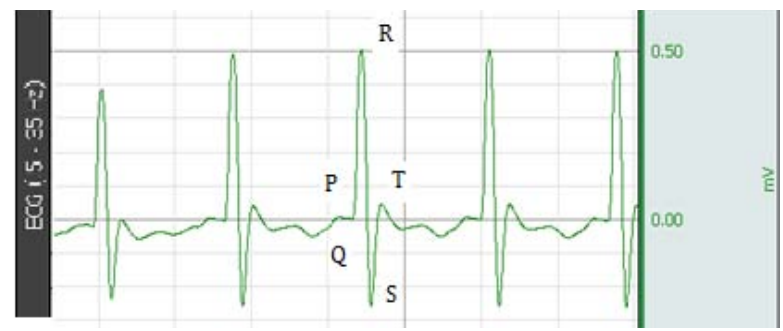

Fig. 2 (V): Effects of OLU on QT interval in ECG of OLU group

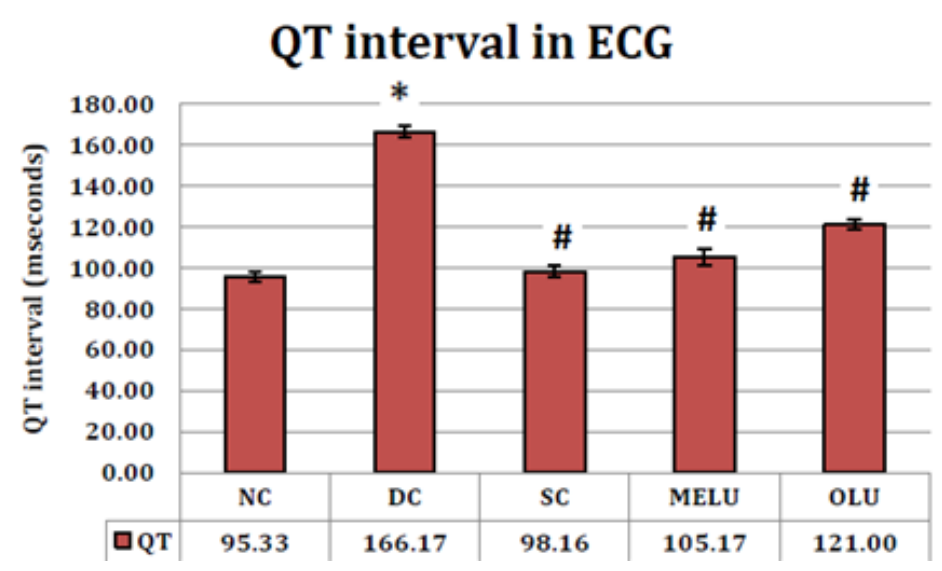

Fig. 3: Beneficial effects of digoxin, MELU and OLU on QT interval in doxorubicin-induced congestive heart failure, $\mathrm{n}=6$, Results were shown as mean \pm SEM, NC-Normal control, DC-Diseases control, SC-Standard control received digoxin (50 $\mu \mathrm{g} / \mathrm{ml}-0.2 \mathrm{ml}$ ), MELU-received methanolic extract of seeds of Linum usitatissimum, (MELU: $500 \mathrm{mg} / \mathrm{ml}-0.2 \mathrm{ml}$ ), *-indicate significant difference in the data compared to control group and \#-indicate significant difference with disease control group at the level of significance was p<0.001 $\approx$ highly significant

Histopathology of cardiac tissues in doxorubicin-induced congestive heart failure model-an in vivo study

Cardiac damage and effect of doxorubicin on the architecture of heart were estimated by histopathological examination of heart tissue. The normal control group showed clear integrity of myocardial membrane, without loss of myofibrils and vacuolization of the cytoplasm. Doxorubicin-treated disease control group's myocardial tissue exhibited clear loss of myofibrils, vacuolization of cytoplasm and dilation of sarcoplasmic reticulum.

Treatment with MELU and OLU showed the least loss of myofibrils and damage to myocardial tissue, which further confirm the effectiveness of seed of Linum usitatissimum in congestive heart failure. 


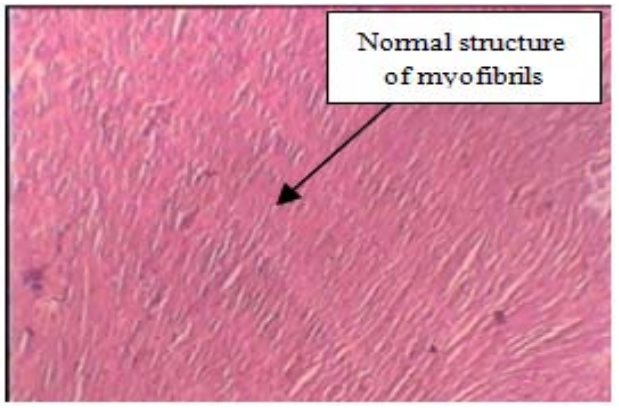

(a) Normal control

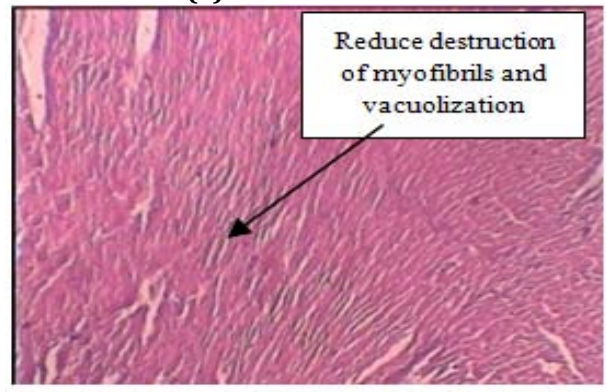

(c) Standard control

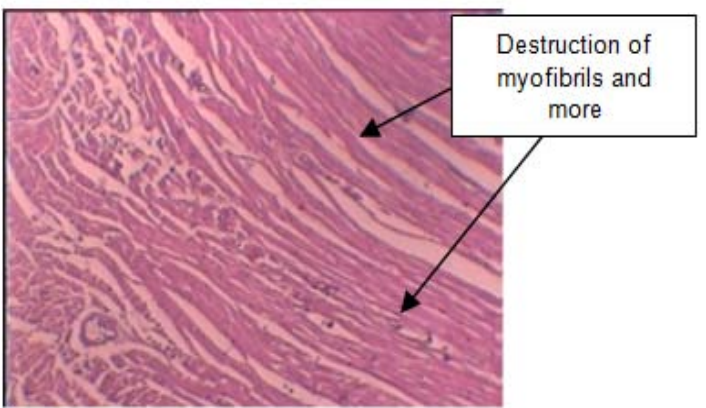

(b) Diseases control

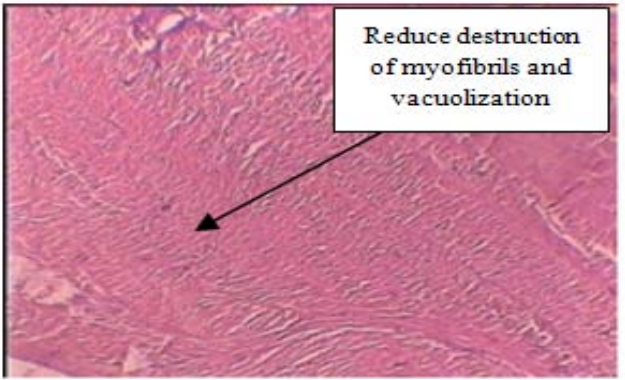

(d) MELU

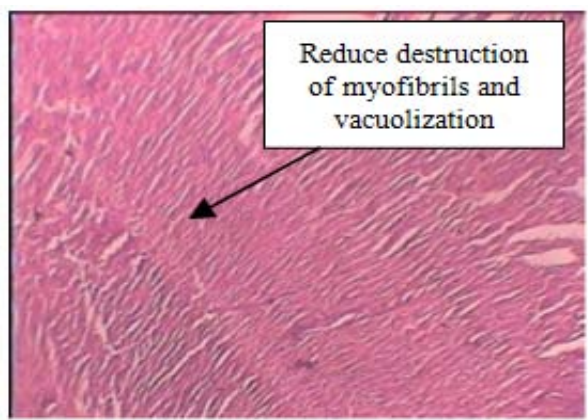

(e) OLU

Fig. 4: Beneficial effects of digoxin, MELU and OLU on histopathology in doxorubicin-induced congestive heart failure model, NC-Normal control, DC-Diseases control, SC-Standard control received digoxin $(50 \mu \mathrm{g} / \mathrm{ml}-0.2 \mathrm{ml})$, MELU-received methanolic extract of seeds of Linum usitatissimum, (MELU: $500 \mathrm{mg} / \mathrm{ml}-0.2 \mathrm{ml}$ )

Beneficial effects of digoxin, methanolic extract and oil of seeds of Linum Usitatissimum on diuretic action of rats in doxorubicin-induced congestive heart failure model-in vivo study

Literature review suggests that diuretic action of the drug have an advantageous effect in the management of CHF. Both MELU and OLU show significantly increased in urine output. Thus it indicates that along with the cardiotonic activity of Linum usitatissimum, it also possesses diuretic activity thus it could be good alternate of digoxin.

MELU showed significantly increased in urine output as compared to normal control, disease control and standard control group while OLU showed a significant difference in normal control and disease group suggested that seeds of Linum usitatissimum can serve one more adventitious tool in the management of congestive heart failure.

Table 2: Diuretic action of methanolic extract and oil of seeds of Linum Usitatissimum

\begin{tabular}{ll}
\hline Groups & Urine (m) \\
\hline Control & $4.0 \pm 0.12$ \\
Diseases & $4.58 \pm 0.15$ \\
Standard Control & $5.66 \pm 0.16 \#$ \\
MELU & $6.58 \pm 0.15 \# *^{*}$ \\
OLU & $5.33 \pm 0.16 \#$ \\
$F$ & 41.48 \\
$d f$ & $29(4,25)$ \\
$P$ & $<0.001$ \\
\hline
\end{tabular}

$\mathrm{n}=6$ and results were shown as mean \pm SEM, Control group-Normal control received water, Disease control group-treated with doxorubicin $(1$ $\mathrm{mg} / \mathrm{kg}$, i. p. for 15 times in $3 \mathrm{w}$, Standard control group-Disease control treated with digoxin $(100 \mu \mathrm{g} / \mathrm{kg}$, p. o. per day) along with doxorubicin, MELU group-Disease control treated with MELU $(500 \mathrm{mg} / \mathrm{kg}$, p. o., per day) along with doxorubicin, OLU group-Disease control treated with OLU $\left(0.6 \mathrm{ml} / \mathrm{kg}\right.$, p. o., per day) along with Doxorubicin, ${ }^{*}$ indicate significant difference in the data compared to normal control group and the level of significance was $\mathrm{p}<0.001 \approx$ highly significant, "indicate significant difference in the data compared to disease control group and the level of significance was $\mathrm{p}<0.001 \approx$ highly significant. 


\section{CONCLUSION}

Above study indicate that methanolic extract of Linum usitatissimum increased positive inotropic effect on Langendorff's assembly indicate cardiotonic activity of Linum usitatissimum. Both MELU and OLU showed decreased in doxorubicin-induced congestive heart failure model. Thus, The Linum usitatissimum is beneficial in management of congestive heart failure because of having positive inotropic, diuretic action and control of rhythmicity of heart.

\section{ACKNOWLEDGEMENT}

I would like to acknowledge with much appreciation the crucial role of the 'Gujarat Council on Science and Technology (GUJCOST)', Government of Gujarat, for providing financial assistance of 1.05 Lac Indian Rupees under research grant of 'Minor Research Project'. I sincerely thank you to the management of School of Pharmacy, RK University to provide research facility and their constant support during the research project. I also thankful to Mr. Kalpesh Limbasiya for his valuable work in the project.

\section{CONFLICT OF INTERESTS}

\section{Declared none}

\section{REFERENCES}

1. Yedy Purwandi Sukmawan. Cilostazol did not induce any adverse reactions in coronary arterial disease (non-st elevation myocardial infarction) with congestive heart failure comorbidity: a case report. Asian J Pharm Clin Res 2013;6 Suppl 5:5-11.

2. Sanjay K Gupta, Surendra H Bodakhe. An elevated pulse pressure: a major risk factor for cardiovascular diseases. Asian J Pharm Clin Res 2013;6 Suppl 5:5-11.

3. Rocco TP, Fang JC. Pharmacology of congestive heart failure. Goodman and gilman's the pharmacological basis of therapeutics. Edited by: Brunton LL, Lazo JS, Parker KL. New York: McGraw-Hill; 2006. p. 869-75.

4. NH Mashour, GI Lim, WH Frishman. Herbal medicine for the treatment of cardiovascular disease. Arch Int Med 1998;158:2225-34.

5. JA Astin. Why patients use alternative medicine? Results of a national study. JAMA 1998;279:1548-53.

6. Agnivesa. Caraka Samhita: English translation and critical exposition based on (Cakrapani Datta's Ayurveda Dipika)/Ram Karan Sharma, Vaidya Bhagwan Dash.Vol. 7. (Chowkhamba Sanskrit Studies); 2002. p. 3304.

7. Srikantha Murthy KR. Bhavaprakasa of bhavamisra. 2. Vol. (Krishna das Academy, Varanasi); 2001. p. 1622.

8. Van Zeist W, Bakker-Heeres JAH. Evidence for linseed cultivation before 6000 BC. J Archaeol Sci 1975;2:215-9.
9. Zohary D, Hopf M. Domestication of plants in the old world: the origin and spread of cultivated plants in West Asia, Europe and the Nile Valley. Oxford, UK: Oxford University Press; 2000.

10. Singh KK, Mridula D, Rehal J, Barnwal P. Flaxseed: a potential source of food, feed and fiber. CRC Crit Rev Food Sci Nutr 2011;51:210-22.

11. Toure $\mathrm{A}, \mathrm{Xu} \mathrm{XM}$. Flaxseed lignans: source, biosynthesis, metabolism, antioxidant activity, bio-active components, and health benefits. Compr Rev Food Sci Food Saf 2010;9:261-9.

12. Simmons CA, Turk P, Beamer S, Jaczynski J, Semmens K, Matak $\mathrm{KE}$. The effect of a flaxseed oil-enhanced diet on the product quality of farmed brook trout (Salvelinusfontinalis) fillets. J Food Sci 2011;76:S192-S197.

13. Murlidharan A. Cardiac stimulant activity of ocimumbasilicum Linn. extracts. Indian J Pharm 2004;36:163-6.

14. Kulkarni SK. Handbook of experimental pharmacology. Vallabh Prakashan. $2^{\text {nd. }}$. Edition; 1993;9:74-6.

15. Chachques JC. Dynamic aortomyoplasty to assist left ventricular failure. Ann Thoracic Surgery 1990;49:225-30.

16. Vogel HG. Drug discovery and evaluation-pharmacological assays, springer-verlag berlin heidelberg New York: Edition $2^{\text {nd; }}$ 2008. p. 118.

17. Singal PK. Subcellular effects of adriamycin in the heart: a concise review. J Mol Cellular Cardiol 1987;19:817-28.

18. Simunek T. Rabbit model for in vivo study of anthracyclineinduced heart failure and for the evaluation of protective agents. Eur J Heart Fail 2004;6:377-87.

19. Koti BC. Cardioprotective effect of lipistat against doxorubicin induced myocardial toxicity in albino rats. Indian J Exp Biol 2009;47:41-6.

20. Gerald F, Di Bona, Sawin LL. Effect of metoprolol administration on renal sodium handling in experimental congestive heart failure. Circulation J Am Heart Assc 1999;100:82-6.

21. Naiyra A. Cardioprotective effect of simvastatin on doxorubicin induced oxidative cardiotoxicity in rats. J Basic Appl Sci 2010;6:29-38

22. Momin FN. Cardioprotective effect of Ixoracoccinealinn. flower extract on doxorubicin induced cardiomyopathy in rats. Pharmacologyonline 2011;3:1145-58.

23. Parial SD. Diuretic activity of the extracts of limoniaacidissima in rats. Rasayan J Chem 2009;2:53-6.

24. Fedman T. Changes in ventricular cavity size: differential effects on QRS and T wave amplitude. Circulation 1985;72:495-501.

25. Holland RP, Brooks H. TQ-ST segment mapping: critical review and analysis of current concepts. Am J Cardiol 1977;40:110-29.

\section{How to cite this article}

- Pravin Tirgar, Limbasiya Kalpesh. Evaluation of beneficial effects of linum usitatissimum in congestive heart failure. Int J Pharm Pharm Sci 2017;9(10):62-66. 